\title{
Assessment of Chromosomal Aneuploidy in Day 3 Cleavage-Stage Embryos and Day 5/6 Blastocysts from Indigenous Black Africans
}

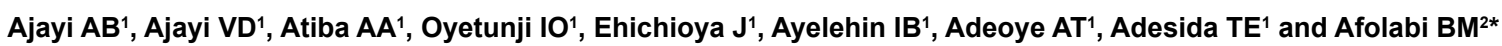

${ }^{1}$ Nordica Fertility Centre, Ikoyi, Lagos, Nigeria

${ }^{2}$ Health, Environment and Development Foundation, Yaba, Lagos, Nigeria

\begin{abstract}
The objectives of this study were to examine the prevalence and to characterize the types of chromosomal aberrations of aneuploidy in cleavage-stage Day 3 human embryos and in Day $5 / 6$ human blastocysts in indigenous Black African women aged $\leq 35$ and $>35$ years. Of the 312 oocytes fertilized for Day 3 embryos and 269 for Day 5/6 blastocysts, 230 blastomeres and 122 blastocysts were biopsied respectively and then subjected to genetic analysis using the array $\mathrm{CGH}$ and next generation sequencing methods, genotyping to characterize chromosomal error types of aneuploidy across all 24 chromosomes. A total of 562 oocytes with $486 \mathrm{MII}$ oocytes, were fertilized from which 230 Day 3 embryos and 122 Day 5/6 blastocysts were biopsied. Euploidy rates in Day 3 embryo group and in Day 5/6 blastocyst group were $24.3 \%$ and $75.0 \%$ respectively while aneuploidy rates were $75.7 \%$ and $25.0 \%$ respectively. Women aged $\leq 35$ years were approximately thrice as likely to have euploid Day 3 embryos (Fisher's $X^{2}=1.18$, p-value $=0.29, \mathrm{OR}=2.79,95 \% \mathrm{Cl}: 0.61,12.67$ ). Blastocyst stage biopsy was more efficient in PGS. Blastocyst culture had some level of aneuploidy selection. Higher diagnosis rate was observed as there was lower rate of embryos with no diagnosis.
\end{abstract}

Keywords: Aneuploidy; Pre-implantation genetic diagnosis; Cleavage-stage; Indigenous Black Africans

\section{Introduction}

In recent times, there has been considerable advancement in the technology of in-vitro fertilization (IVF) not only for infertility but also for pre-implantation genetic diagnosis (PGD). The process of PGD was initially applied to diagnose sex-linked disorders, monogenic disorders or chromosomal structural abnormalities and also to test for HLA compatibility. However, genetic testing in IVF evolved to include the screening of numerical chromosomal abnormalities which is referred to as PGD aneuploidy screening or simply PGS (Pre-implantation genetic screening)Fh. Aneuploidy has been regarded as one of the main reasons for failure of implantation [1-4]. Aneuploidy is also regarded as the leading cause of spontaneous abortion and mental retardation in women of older age $[5,6]$ and the study of chromosomal aberrations in embryos is because, it is believed that, these aberrations contribute significantly to spontaneous abortion and recurrent implantation failure in women, irrespective of age, who experience unexplained infertility $[7,8]$. Studies have reported that early-stage embryos often suffer from chromosomal abnormalities [9-12] and that over 50\% of human embryos produced through IVF contain aneuploidy cells [9-11]. The undesirable outcomes of chromosomal aberration include failure to implant, spontaneous abortion and foetus with trisomic condition [1317]. Pre-implementation screening (PGS) to detect aneuploidy within embryos is progressively performed in IVF, with the goal of improving the efficacy of infertility management [18]. Pre-implementation genetic screening allows investigation of ploidy across all 24 chromosomes, but this technology is relatively new in sub-Saharan Africa. The incidence of spontaneous abortion in sub-Saharan Black Africa is unknown. Much more surprising is that the cause of spontaneous abortion or babies born with chromosomal disorders such as Trisomy 21 is hardly reported in studies of children with such disorders. There is a lacuna regarding data on chromosomal abnormalities among indigenous Black Africans. However, in the past decade or so, probably due to more awareness, women now come forward to request for pre-implantation genetic screening due to having previous abnormal babies, recurrent miscarriages, having babies with congenital abnormalities, genotype or sex selection. Even if these women do not request for it but their medical history indicates any of the above, except for sex selection, they are advised to consider PGD to which they almost always acquiesce. Nordica Fertility Centre follows the policy that it is ethically wrong to transfer an abnormal embryo.

The first study describing successful biopsy of a human embryo for PGD was performed in 3-day-old embryos, which consisted of 6-8 cleavage-stage cells [19-21]. Currently, biopsies of 8-cell blastomeres or blastocyst trophectoderm obtained on day 3 or 5/6 are performed in IVF laboratories worldwide [21-23]. A European study on preimplementation genetic aneuploidy screening in 11 embryos found four (36.4\%) to be aneuploid [24]. Part of the conclusion from the study of Rabinowitz and colleagues in California was that chromosome gains were predominantly maternal in origin whereas chromosome losses were not biased in terms of parental origin of chromosome [25]. While a study from Florida, USA, stated that the availability of euploid embryos is associated with high ongoing pregnancy and implantation rates and the absence of euploid embryos for transfer predicts poor reproductive outcome [26], another from Houston, Texas reported that aneuploidy rates in day 7 human blastocysts produced by IVF are very high [27]. Chromosomal abnormalities are categorized into two types: numerical and structural. Numerical abnormalities involve the addition (trisomy, tetrasomy, etc) or deletion (monosomy) of an entire chromosome which is called aneuploidy, and the addition or

*Corresponding author: Afolabi BM, Health, Environment and Development Foundation, 34 Montgomery Road, Yaba, Lagos, Nigeria, Tel: +234 080049 0729. E-mail: bmafolabi@gmail.com

Received March 12, 2018; Accepted March 27, 2018; Published April 02, 2018

Citation: Ajayi AB, Ajayi VD, Atiba AA, Oyetunji IO, Ehichioya J, et al. (2018) Assessment of Chromosomal Aneuploidy in Day 3 Cleavage-Stage Embryos and Day 5/6 Blastocysts from Indigenous Black Africans. Human Genet Embryol 8: 147. doi:10.4172/2161-0436.1000147

Copyright: (C) 2018 Ajayi AB, et al. This is an open-access article distributed under the terms of the Creative Commons Attribution License, which permits unrestricted use, distribution, and reproduction in any medium, provided the original author and source are credited. 
deletion of an entire set of chromosomes is referred to as polyploidy and haploidy, respectively. Aneuploidy has been reported to occur in approximately $20 \%$ of cleavage-stage human embryos [28] with an increase to $45 \%$ of cleavage-stage embryos taken from patients with advanced maternal age (AMA; $>36$ years) [29]. Whereas, polyploidy and haploidy occur much less frequently (in $7 \%$ and $3 \%$ cleavage-stage embryos, respectively) [29] on the other hand, Structural chromosomal abnormalities refer to when the structure of a chromosome is altered and can occur spontaneously or as a result of external forces such as radiation. An embryo can present with both numerical and structural abnormalities concurrently. Although, aneuploidies are naturally prevented as most are incompatible with life however, Some aneuploidies have been seen to persist through implantation resulting in a live birth for trisomy 21 (Down syndrome), trisomy 13 (Patau syndrome), trisomy 18 (Edwards syndrome), monosomy X (Turner syndrome) and trisomy XXY (Klinefelter syndrome). Trisomies 13, 18 , and 21 have been implicated in the etiology of early pregnancy loss. The occurrence of these aneuploidies in human embryos poses to be a major drawback in IVF, compromising the efficiency in achieving healthy live birth, hence the advent of PGS aneuploidy screening in IVF. Advancement in media culture permitted the growth of embryos in-vitro up to the blastocyst stage which has facilitated the evolution of PGS to include trophectoderm cell biopsy [30]. Here, several trophectoderm cells are removed and screened for aneuploidy whereas cleavage stage biopsy involves one or two blastomeres with cleavagestage biopsy [30,31]. McArthur et al. [32] reported the first routine use of blastocyst biopsy with florescent in situ hybridization FISH in human pre-implantation embryos to produce successful pregnancies and live births.

\section{Indications for PGS}

The main indications for the use of PGS in IVF treatments include advanced maternal age (AMA), repeated implantation failure (RIF), and recurrent pregnancy loss (RPL). It is well known that the rate of chromosome abnormalities is higher in patients with AMA and RPL. Also, PGS has been used in women with previous trisomic conceptions [33], women who have partners with male factor infertility [34-36], and sometimes in egg donor cycle [37]. Today, the use of PGS for healthy patients with no indications for the purpose of improving IVF outcomes is on the rise however, in this part of the world, the major indication for PGS has remained for gender balancing.

\section{Correction mechanism}

It has been established that Mitotic errors are common in human preimplantation embryos occurring highest during the first three cleavages after fertilization resulting in about three quarters of human preimplantation embryos affected by aneuploidies and mosaicsm at day three of development. However, at later developmental stages such as the blastocyst stage, the mitotic aneuploidy rate is lower which could be explained by the fact that apoptotic mechanisms which could deselect against aneuploid cells are very low in cleavage stage with a significant increase at the blastocyst stage.

In regard to self-correction mechanisms, it is assumed that during blastocyst development, the embryo experiences a stringent selfcorrection probably based on cell cycle checkpoint control mechanisms such as cell arrest, apoptosis, active correction of the aneuploidies and preferential allocation of the aneuploid cells to the extra-embryonic tissues. Thus, to form a blastocyst, the embryo must successfully undertake the first cellular differentiation and epigenetic modification to form the trophectoderm (TE) and inner cell mass (ICM)]; this process may be hampered by the inappropriate gene expression that inevitably accompanies aneuploidy. In the case of mosaic embryos, aneuploid cells could arrest development in favor of euploid ones [38]. We can therefore assume that blastocyst formation from cleavage stage is a form of selection of euploid embryos involving some level of selfcorrection. Li et al. [39] did a comparison of sequential chromosomal data on the two developmental stages, day-3 and subsequently on day- 5 with both stages tested with five-chromosome FISH, they observed $40 \%$ aneuploid embryos on day-3 were euploid on day-5. In 2008, BarbashHazan et al. [40] re-analyzed 83 abnormal day-3 embryos out of which 27 embryos (32.6\%) underwent self-normalization. More interestingly, $41 \%$ of the abnormal embryos diagnosed as trisomic underwent trisomic rescue (which is the loss of a chromosome in trisomic cells). Another recent study by Northrop et al. [41] demonstrated similar results with re-analysis of blastocyst-stage embryos using SNP microarray-based 24 chromosome aneuploidy screening which revealed $65 \%$ of the monosomic, $47 \%$ of the trisomic, and $63 \%$ of the complex aneuploid embryos were euploid at the blastocyst stage. Hence, Northrop et al. [41] found a significant number of euploid blastocyst-stage embryos that were previously diagnosed as aneuploid on day 3. This selfcorrection mechanism may also be due to monosomic or trisomic rescue as suggested by some studies [40-42].

\section{Day 3 versus day 5 biopsy}

This important aspect of preimplantation embryo screening needs to be considered in order to prevent possible erroneous disposal of euploid blastocysts that were previously diagnosed as abnormal at the cleavage stage [41]. Hence the birth of the ESHRE report on PGD/ PGS which recommends a shift from cleavage stage biopsy towards trophectoderm biopsy [43] due to the high degree of mosaicism of cleavage stage embryos [44]. Blastocyst biopsy is rapidly becoming the more preferred biopsy method for aneuploidy screening. Biopsy at the blastocyst stage has been demonstrated to be more desirable since embryos at this stage have a smaller risk of aneuploidy (38.8\%) than embryo biopsy at the cleavage stage (51\%) mostly since aneuploid cells in cleavage stage embryos are more likely not to develop into blastocyst stage involving some sort of de-selection of aneuploid embryos. Furthermore, the major limiting factor trophectoderm biopsy which is the length of time of genetic analysis has been solved with the optimization of blastocyst cryopreservation by vitrification especially for IVF clinics that send their biopsy samples to an external genetic lab for analysis. Some studies have concluded that there is a better implantation rates across all ages for euploid blastocyst transfer following Day $5 / 6$ biopsy rather than blastocyst transfer subsequent to day 3 biopsy. This could be influenced by varying factors such as may be due to less damage to the embryo during trophectoderm biopsy, higher accuracy of day 5/6 PGS due to a larger amount of genetic material can be retrieved from biopsy and better uterine receptivity when the blastocysts are cryopreserved following biopsy and transferred in a controlled endometrium development (CED) cycle [45]. Therefore, the main objective of this study was to compare the prevalence and characteristics of chromosomal aberrations of aneuploidy in cleavagestage Day 3 human embryos and in Day 5/6 human blastocysts among indigenous Black Africans. The main hypothesis is that euploid embryos are more prevalent in women 35 years or less than in older women or vice versa.

\section{Materials and Methods}

\section{Ethical statement}

Patients undergoing IVF, egg donation and PGS signed written 
consents for all kinds of laboratory and clinical procedures. All egg donors were anonymous in the present study. The data was retrospectively collected from the medical records at the clinic from September 2012 to August 2014 and the study was approved by Nigerian Institute for Medical Research Institutional Review Board (NIMR-IRB 18-006).

We retrospectively evaluated an analysis of 352 embryos from 45 ICSI/PGS cycles including oocyte donor cycles from 35 couples for aneuploidy screening and gender selection at our clinic from June 2014 to August 2017. We assigned the couples into two groups according to biopsy day: day 3 ( 230 embryos, 29 cycles) and day 5/6 (122 blastocysts, 16 cycles). Within each biopsy group, the data was further broken down into two age groups, $\leq 35$ and $>35$ years of age at the time of cycle start. All couples presenting for chromosome aneuploidy testing and gender selection had one or two blastomeres biopsied from their embryos, providing that the embryo had $\geq 8$ blastomeres with less than $10 \%$ fragmentation rate on day 3 and 2-5 trophectoderm cells from day $5 / 6$ blastocysts post-oocyte collections. Egg source were aged 29.6 \pm 9.4 years and $28.9 \pm 7.1$ years, respectively. All patients signed an informed consent form for ICSI/PGS that included counselling on the IVF program, risk of ovarian hyperstimulation syndrome, probability of pregnancy, risk of pregnancy complications, risk of misdiagnosis, necessity of a prenatal diagnosis, and possible cryopreservation of supernumerary embryos obtained during the program and risk of no suitable embryos for transfer. Embryo transfer was cancelled in cycles without embryos reaching blastocyst stage for day 3 biopsy or without euploid embryos in both groups. Chaotic embryos (complex abnormal) were defined as those showing a complex pattern of aneuploidies, involving more than six chromosomes.

\section{Patient stimulation and egg retrieval}

Patients were subjected to ovarian stimulation with the use of gonadotropins (follicle-stimulating hormone or human menopausal gonadotropin), and gonadotropin-releasing hormone analogues or antagonists were used for controlled ovarian hyperstimulation. Patients received human chorionic gonadotropin when the diameter of the three leading follicles was $>18 \mathrm{~mm}$. Ultrasound-guided oocyte retrieval was performed 34-36 hours depending on protocol used after the human chorionic gonadotropin injection, and luteal support consisting of progesterone injections were provided. Only Oocytes at MII were microinjected with ejaculated spermatozoa by intracytoplasmic sperm injection (ICSI). Fertilization check was carried out approximately 18 hours after the procedure to confirm the presence of two pronuclei and extrusion of the second polar body. Normally fertilized oocytes were further cultured until either day- 3 or day-5/6 of embryo development before and after biopsy by using standard embryo culture conditions in our laboratory. Embryo culture was done at $37^{\circ} \mathrm{C}$ in a humidified atmosphere of $5 \% \mathrm{CO}_{2}$ in a one-step single culture medium under oil for all phases of embryo development (SAGE 1-Step, ORIGIO, Denmark). From July 2016, the PGS screening process was updated in our clinic to involve biopsy at the blastocyst stage as well as use of NGS. Therefore, in total 45 PGS cycles were included in the study comprising of 29 cycles of day 3 analysis using array CGH and 16 cycles of day $5 / 6$ biopsy using NGS. Day 3 biopsy was performed on 126 embryos from 18 cycles, and day 5/6 biopsy was performed on 150 embryos from 20 cycles. In all cases, a Leica DM IRB inverted microscope (Wetzlar, Germany), equipped with a Narishige NT-88 3D hydraulic micromanipulator (Tokyo, Japan) and Origio microtools were used for micromanipulation. A total of eight (8) cycles with day 3 biopsy ended with no embryo transfer as there were no euploid embryos for transfer while all cycles with day 5/6 had euploid embryos to transfer. Oocytes were inseminated using conventional IVF techniques. Embryo biopsy took place either on the morning of day-3 of embryo development or at blastocyst stage, usually on day- 5 but on day- 6 for some embryos growing at a slower rate. Biopsy was performed using laser assisted hatching followed by removal of one or two blastomere cell (cleavage stage biopsy) or 2-5 cells of trophectoderm tissue (blastocyst biopsy). The biopsied material was washed in clean biopsy wash medium (supplied by Igenomix, Spain). Following washing, the cell or tissue was placed in the supplied transport tube labelled with the patient initials and embryo number and kept on ice until being shipped to the genetic lab for testing. All samples were shipped by custom courier or commercial shipping companies and delivered to the genetic laboratory within two days for testing.

\section{Day 3 biopsy}

Embryos were de-compacted in $\mathrm{Ca}^{2+} / \mathrm{Mg}^{2+}$-free biopsy media. For the cases of day-3 embryo biopsy, only embryos with five or more nucleated blastomeres and less than 25\% fragmentation degree were biopsied. Day- 3 embryo biopsy can be summarized as follows: embryos were placed on a droplet containing $\mathrm{Ca}^{2+} / \mathrm{Mg}^{2+}$-free medium (LifeGlobal, Guilford, CT), the zona pellucida was perforated by pulses of laser using the ZILOS-tkTM laser system (Hamilton Thorn Bioscience Inc., MA USA), and one or two blastomere (s) was withdrawn from each embryo, then individual blastomeres were placed in $0.2 \mathrm{~mL}$ PCR tubes containing $2 \mu \mathrm{L}$ PBS. For blastomere washing and handling, $1 \%$ polyvinylpyrrolidone (PVP) was used. PCR tubes were immediately frozen at $-20^{\circ} \mathrm{C}$ and kept in the freezer until transportation to the genetic analysis laboratory. Embryo culture was continued till day 5/6 for results and euploid embryos were candidates to be transferred on day $5 / 6$ while excess euploid embryos were vitrified either on day 5 or on day 6.

\section{Day 5 biopsy}

Blastocyst biopsy was performed on TE cells at days 5 and 6 depending on blastocyst development. At day 3, a hole about $20 \mu \mathrm{m}$ was opened in the zona pellucida to facilitate blastocyst hatching using the ZILOS-tkTM laser system (Hamilton Thorn Bioscience Inc., MA (USA). On day 5/6, embryos for biopsy were examined with an inverted microscope, and if the embryos developed to a full blastocyst stage and some trophectoderm (TE) cells started to hatch from the opening in the zona pellucida, some hatched TE cells $(3 \sim 10)$ were biopsied using a 20 $\mu \mathrm{m}$ polished biopsy pipette with assisted cutting by the laser. All biopsy procedures were performed in droplets of buffered medium (HEPES, Sage in-vitro fertilization, Inc., Trumbull, CT, USA) overlaid with mineral oil on the heated stage of a Nikon IX-70 microscope, equipped with micromanipulation tools. After biopsy, the embryo was cultured in SAGE one-step medium for 1-3 hours before cryopreservation. The biopsied cells were washed with a washing buffer provided and placed in tubes with cell lysis buffer and were then frozen at $-20^{\circ} \mathrm{C}$ before being shipped to the genetic laboratory. For samples biopsied on day- 5 or day- 6 of embryo development, resulting blastocysts were cryopreserved using the cryotop vitrification method after which euploid embryos were transferred in a frozen embryo transfer cycle (FET) into a uterus free of gonadotropin stimulation.

\section{Microarray comparative genomic hybridization (aCGH)}

Microarray-CGH was performed as stated previously by Rodrigo et al., [46]. Briefly, following sample receipt in the lab, each tube was opened in a dedicated DNA amplification clean-room, under laminar 
Citation: Ajayi AB, Ajayi VD, Atiba AA, Oyetunji IO, Ehichioya J, et al. (2018) Assessment of Chromosomal Aneuploidy in Day 3 Cleavage-Stage Embryos and Day 5/6 Blastocysts from Indigenous Black Africans. Human Genet Embryol 8: 147. doi:10.4172/2161-0436.1000147

Page 4 of 10

flow conditions, and the amplification reagents were added (SurePlex, Rubicon Genomics Inc, Ann Arbor, MI, USA/BlueGnome LTD, CPC4, Capital Park, Fulbourn, Cambridge, UK). Following amplification according to the manufacturer's instructions, each sample was loaded onto an agarose gel to check for amplification. A smear of DNA, observed on the gel following electrophoresis, is indicative of positive amplification. All samples that were positive for DNA amplification were taken to the fluorescent labelling steps. Labelling was performed using manufacturer's recommendations with Cy3 dye for test DNA and Cy5 dye for reference male DNA (BlueGnome LTD). After labelling, embryo biopsy samples and reference DNA samples were separately denatured at $74^{\circ} \mathrm{C}$ prior to being mixed together and added to each microarray. Microarrays were hybridized at $47^{\circ} \mathrm{C}$ for at least 4 hours or overnight in a humidified chamber. Following hybridization, each microarray was washed as follows: 10 minutes in $2 \mathrm{x}$ SSC/0.05\% Tween 20 at room temperature, 10 minutes in $1 \mathrm{x} \mathrm{SSC}$ at room temperature, 5 minutes in $0.1 \mathrm{x} \mathrm{SSC}$ at $60^{\circ} \mathrm{C}$ and 2 minutes in $0.1 \mathrm{x} \mathrm{SSC}$ at room temperature. Each microarray was then scanned for green fluorescence at $632 \mathrm{~nm}$ and for red fluorescence at $587 \mathrm{~nm}$. Raw images were loaded automatically into BlueFuse software (BlueGnome LTD) allowing for automated evaluation of fluorescent signals. Each sample was scored by a trained technologist who assessed all 24 chromosomes, noting all gains and losses, as well as determining the gender of each sample. A second technologist then scored the sample blindly, with no knowledge of the initial score by technologist number one. A final score for each sample was assigned by comparing the score of technologist one with technologist two. Any discrepancies were noted and were adjudicated by a third technologist and/or the laboratory supervisor or director. Once results for all samples from each patient were finalized, a diagnostic report was prepared and shared with the physician ahead of embryo transfer. Transfer of euploid embryos typically took place on the morning of day- 5 or day- 6 for cleavage stage biopsy.

\section{Next - Generation Sequencing (NGS) analysis}

Rapid NGS (Next Generation Sequencing) (Thermo Fisher Scientific, Inc., MA, USA) analysis was carried at the genetic laboratory as described by Treff et al., [47]. Libraries were prepared using the Ion ReproSeq PGS kit (Thermo Fisher scientific, Inc., MA, USA). Ion Reporter software v 5.0 was used for data analysis using ReproSeq Low-pass whole-genome aneuploidy workflow v 1.0 to detect 24 chromosomes aneuploidies from a single whole genome sample with low coverage (minimum 0.01x). Normalization is done using the bioinformatics baseline ReproSeq Low-coverage Whole-Genome Baseline (5.0) generated from multiple normal samples. Although the NGS was used for the analysis of the blastocyst stage different from the method of a-CGH used for the cleavage stage embryos, this does not impact the study as the concordance between the two genetic methods of a-CGH and NGS are about $100 \%$ as proven by various studies $[48,49]$.

\section{Embryo vitrification}

The Cryotop method was used to vitrify embryos as previously described by Kuwayama et al. [30].

\section{Results}

The means ( \pm sd) of age and Body Mass Index of all egg sources of Day 3 embryos were 29.8 (4.3) years and $25.3(5.3) \mathrm{kg} / \mathrm{m}^{2}$ respectively while the mean $( \pm \mathrm{sd})$ age and Body Mass Index of all egg sources of Day $5 / 6$ blastocyst were $28.9(3.5)$ years and $23.6(6.5) \mathrm{kg} / \mathrm{m}^{2}$ respectively (Table 1 ). The ICSI/PGS day 3 and day $5 / 6$ groups did not differ significantly in age; egg source were aged $29.6 \pm 9.4$ years and $28.9 \pm 7.1$ years, respectively. Of the Day 3 embryos, there were 25 (86.2\%) egg sources aged 35 years or younger while there were 4 (14.8\%) older than

\begin{tabular}{|c|c|c|c|c|c|c|c|c|c|c|c|c|c|c|c|c|c|c|}
\hline \multirow{4}{*}{ Variables } & \multirow{4}{*}{ Items } & \multirow{4}{*}{ Statistics } & \multicolumn{8}{|c|}{ Day 3 Embryo } & \multicolumn{8}{|c|}{ Day 5 Blastocyst } \\
\hline & & & \multicolumn{6}{|c|}{ Egg source } & \multirow{2}{*}{\multicolumn{2}{|c|}{ Recipient }} & \multicolumn{6}{|c|}{ Egg source } & \multirow{2}{*}{\multicolumn{2}{|c|}{ Recipient }} \\
\hline & & & \multicolumn{2}{|c|}{ Total } & \multicolumn{2}{|c|}{ Donor } & \multicolumn{2}{|c|}{ Own } & & & \multicolumn{2}{|c|}{ Total } & \multicolumn{2}{|c|}{ Donor } & \multicolumn{2}{|c|}{ Own } & & \\
\hline & & & Freq. & $\%$ & Freq. & $\%$ & Freq. & $\%$ & Freq. & $\%$ & Freq. & $\%$ & Freq. & $\%$ & Frec & $\%$ & Freq. & $\%$ \\
\hline \multirow{6}{*}{$\begin{array}{c}\text { Age } \\
\text { (years) }\end{array}$} & \multirow{2}{*}{ All } & Freq. (\%) & 29 & 100.0 & 19 & 65.5 & 10 & 34.5 & 29 & 100.0 & 16 & 100.0 & 12 & 75.0 & 4 & 25.0 & 16 & 100.0 \\
\hline & & Mean $( \pm S D)$ & \multicolumn{2}{|c|}{$29.6(4.3)$} & \multicolumn{2}{|c|}{$27.1(1.7)$} & \multicolumn{2}{|c|}{$34.5(3.4)$} & \multicolumn{2}{|c|}{$40.8(6.7)$} & \multicolumn{2}{|c|}{$28.9(3.5)$} & \multicolumn{2}{|c|}{$27.3(1.7)$} & \multicolumn{2}{|c|}{$33.8(2.9)$} & \multicolumn{2}{|c|}{$40.9(5.5)$} \\
\hline & \multirow{2}{*}{$\leq 35$} & Freq. (\%) & 25 & 86.2 & 19 & 76.0 & 6 & 24.0 & 6 & 20.7 & 14 & 87.5 & 12 & 100.0 & 2 & 50.0 & 2 & 12.5 \\
\hline & & Mean $( \pm \mathrm{SD})$ & \multicolumn{2}{|c|}{$28.7(3.3)$} & 27.1 & 1.7) & 32.7 & $(3.4)$ & 32.7 & $(3.4)$ & 27.9 & (2.3) & 27.3 & 1.7) & 31. & $5(2.1)$ & 31.5 & $(2.1)$ \\
\hline & $>35$ & Freq. (\%) & 4 & 13.8 & 0 & 0.0 & 4 & 100.0 & 23 & 79.3 & 2 & 12.5 & 0 & 0.0 & 2 & 50.0 & 14 & 87.5 \\
\hline & $>35$ & Mean $( \pm S D)$ & 37.3 & (1.5) & - & & 37.3 & $(1.5)$ & 42.4 & $(6.2)$ & 36.0 & $(0.0)$ & . & & 36. & $(0.0)$ & 42.3 & (44.4) \\
\hline & A" & Freq. (\%) & 29 & 100.0 & 19 & 65.4 & 10 & 34.6 & - & - & 15 & 100.0 & 11 & 73.3 & 4 & 26.7 & - & - \\
\hline & All & Mean $( \pm S D)$ & 25.3 & (5.3) & 22.2( & 2.8) & 31.1 & (3.7) & - & - & 23.6 & $(6.5)$ & 20.7 & 1.6) & & $5(8.7)$ & - & - \\
\hline & & Freq. (\%) & 0 & 0.0 & 0 & 0.0 & 0 & 0.0 & - & - & 1 & 6.7 & 1 & 9.1 & 0 & 0.0 & - & - \\
\hline & $<18.5$ & Mean $( \pm \mathrm{SD})$ & & - & - & & - & & - & - & 18.1 & $(0.0)$ & 18.1 & $0.0)$ & & - & - & - \\
\hline & $185-245$ & Freq. (\%) & 19 & 65.5 & 18 & 94.7 & 1 & 5.3 & - & - & 11 & 73.3 & 10 & 90.9 & 1 & 25.0 & - & - \\
\hline $\begin{array}{c}\mathrm{BMI}(\mathrm{Kg} / \\
\left.\mathrm{m}^{2}\right)\end{array}$ & $18.5-24.5$ & Mean $( \pm S D)$ & 21.6 & $(1.5)$ & 21.6 & 1.5) & - & & - & - & 20.9 & $(1.4)$ & 21.0 & 1.4) & 20. & $3(0.0)$ & - & - \\
\hline & ת & Freq. (\%) & 3 & 10.4 & 0 & 0.0 & 3 & 33.3 & - & - & 0 & 0.0 & 0 & 0.0 & 0 & 0.0 & - & - \\
\hline & $25.0-29.9$ & Mean $( \pm S D)$ & 26.6 & $(0.4)$ & - & & 26.6 & $(0.4)$ & - & - & 0.0 & $0.0)$ & & & & - & - & - \\
\hline & & Freq. (\%) & 7 & 24.1 & 1 & 5.9 & 6 & 66.7 & - & - & 3 & 20.0 & 0 & 0.0 & 3 & 75.0 & - & - \\
\hline & $\geq 30$ & & & & & & & & & & & & & & & & & \\
\hline & & ean $( \pm \mathrm{SD})$ & 33.1 & (1.9) & 31.2 & $0.0)$ & 33.4 & (1.9) & - & - & 35.2 & (5.5) & & & 35. & $2(5.5)$ & - & - \\
\hline & Sex selection & & & & $27(9$ & $3.1 \%)$ & & & & - & & & $13(81$ & $2 \%)$ & & & & - \\
\hline & $\begin{array}{l}\text { Genotype and } \\
\text { sex selection }\end{array}$ & & & & $2(6$ & $9 \%)$ & & & 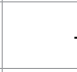 & - & & & $2(12$ & $5 \%)$ & & & & - \\
\hline $\begin{array}{c}\text { Reason for } \\
\text { PGD }\end{array}$ & $\begin{array}{c}\text { Aneuploidy } \\
\text { screening }\end{array}$ & Freq. (\%) & & & $0(0$ & $0 \%)$ & & & . & - & & & $1(6$. & $\%)$ & & & & - \\
\hline & $\begin{array}{c}\text { Others } \\
\text { (Advanced age) }\end{array}$ & & & & $0(0$ & $0 \%)$ & & & . & - & & & $0(0$. & $\%)$ & & & & - \\
\hline & Statis & & & & $x^{2}=0.51$ & P-valu & $u=0.47$ & ; Odds & Ratio $=$ & $3.12 ; 95$ & $5 \%$ Conf & dence It & terval: 0 & $46,20$. & & & & \\
\hline
\end{tabular}

Table 1: Socio-demographic characteristics of egg source and recipients. 
Citation: Ajayi AB, Ajayi VD, Atiba AA, Oyetunji IO, Ehichioya J, et al. (2018) Assessment of Chromosomal Aneuploidy in Day 3 Cleavage-Stage Embryos and Day 5/6 Blastocysts from Indigenous Black Africans. Human Genet Embryol 8: 147. doi:10.4172/2161-0436.1000147

Page 5 of 10

35 years of age; while $14(87.5 \%)$ egg sources of Day $5 / 6$ blastocysts were aged 35 years and younger with $2(12.5 \%)$ aged over 35 years. In general, the mean age of recipients of Day 3 embryos ( 40.8 years)

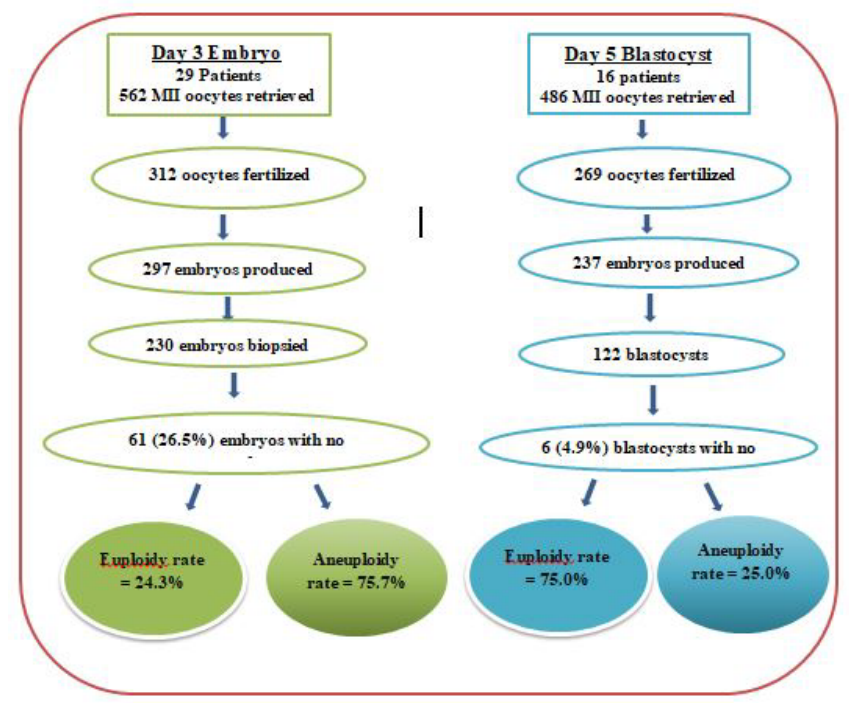

Figure 1: Diagraph of patient population, embryo/blastocyst developments and aneuploidy rates. was significantly different $(t=-10.5, \mathrm{df}=33.3, \mathrm{P}$-value $=0.00001)$ from that of the donors used in the donor cycles (27.1 years). Likewise, there was a noteworthy disparity $(\mathrm{t}=-9.32, \mathrm{df}=18.7, \mathrm{P}$-value $=0.00001)$ in the mean age of recipients of Day $5 / 6$ blastocysts (40.9 years) and that of the donors (27.3 years).

As depicted in Figure 1, 562 and 486 MII oocytes from 29 cycles in the Day 3 embryo study group and 16 cycles in Day 5/6 blastocyst study group respectively, were obtained. In the day 3 embryo study group 312 oocytes were fertilized compared to 269 in the Day 5/6 blastocyst study group producing 297 Day 3 embryos out of which 230 embryos were biopsied and for Day 5/6 group, 122 blastocysts were formed and biopsied from 237 embryos for chromosomal anomalies. Sixty-one embryos and 6 blastocysts had no results, giving an overall euploidy rate of $24.3 \%$ and aneuploidy rate of $75.7 \%$ in Day 3 embryo group and euploidy rate of $75.0 \%$ and aneuploidy rate of $25.0 \%$ in Day $5 / 6$ blastocyst study group.

Of the 562 MII oocytes retrieved from Day 3 embryo group, 506 $(90.0 \%$; mean $[ \pm \mathrm{sd}]=20.2[8.9])$ were from women aged $\leq 35$ years and $56(10.0 \%$; mean $[ \pm \mathrm{SD}]=14.0[3.4])$, signifying a statistically significant difference $(\mathrm{t}=10.3, \mathrm{df}=160.0, \mathrm{P}$-value $=0.00001)$ (Table 2). Likewise, of the 486 MII oocytes retrieved from Day 5/6 blastocyst group, $422(86.8 \%$; mean $[ \pm \mathrm{sd}]=30.1[12.2])$ were from women aged $\leq 35$ years and $64(13.2 \%$; mean $[ \pm \mathrm{sd}]=32.0[1.4])$ from their older counterparts, also signifying a statistically significant difference $(\mathrm{t}=$ -

\begin{tabular}{|c|c|c|c|c|c|c|c|c|}
\hline \multirow{2}{*}{ Variables } & \multicolumn{4}{|c|}{ Day 3 embryos (PGD cycles=29) } & \multicolumn{4}{|c|}{ Day 5 Blastocysts (PGD cycles=16) } \\
\hline & Total & Mean ( \pm SD) & Median & Range & Total & Mean ( \pm SD) & Median & Range \\
\hline \multirow{5}{*}{ Oocyte retrieval } & 44 & $1.5(0.6)$ & 1 & $2(1-3)$ & 22 & $1.4(0.6)$ & 1 & $1-3$ \\
\hline & \multicolumn{4}{|c|}{ Age $\leq 35$ y $(n=25)$} & \multicolumn{4}{|c|}{ Age $\leq 35$ y $(n=14)$} \\
\hline & 36 & $1.4(0.6)$ & 1 & $2(1-3)$ & 18 & $1.3(0.6)$ & 1 & $1-3$ \\
\hline & \multicolumn{4}{|c|}{ Age $>35$ y $(n=4)$} & \multicolumn{4}{|c|}{ Age $>35$ y $(n=2)$} \\
\hline & 8 & $2.0(0.8)$ & 2 & $2(1-3)$ & 4 & $2.0(0.0)$ & 2 & $2-2$ \\
\hline \multirow{5}{*}{ MII Oocyte retrieved } & 562 & $19.4(8.6)$ & 16 & $30(7-37)$ & 486 & $30.4(11.4)$ & 29 & $38(17-55)$ \\
\hline & \multicolumn{4}{|c|}{ Age $\leq 35$ y $(n=25)$} & \multicolumn{4}{|c|}{ Age $\leq 35$ y $(n=14)$} \\
\hline & 506 & $20.2(8.9) !$ & 18 & $30(7-37)$ & 422 & $30.1(12.2)$ & 26.5 & $38(17-55)$ \\
\hline & \multicolumn{4}{|c|}{ Age $>35$ y $(n=4)$} & \multicolumn{4}{|c|}{ Age $>35$ y $(n=2)$} \\
\hline & 56 & $14.0(3.4) !$ & 15.5 & $7(9-16)$ & 64 & $32.0(1.4)$ & 32.0 & $31-33$ \\
\hline \multirow{5}{*}{ Oocyte fertilized } & 312 & $10.8(4.4)$ & 9 & $5-23$ & 269 & $16.8(8.6)$ & 14.5 & $10-45$ \\
\hline & \multicolumn{4}{|c|}{ Age $\leq 35$ y $(n=25)$} & \multicolumn{4}{|c|}{ Age $\leq 35$ y $(n=14)$} \\
\hline & 275 & $11.0(4.7)$ & 9 & $18(5-23)$ & 228 & $16.3(9.1)$ & 14 & $35(10-45)$ \\
\hline & \multicolumn{4}{|c|}{ Age $>35$ y $(n=4)$} & \multicolumn{4}{|c|}{ Age $>35$ y $(n=2)$} \\
\hline & 37 & $9.2(1.7)$ & 9.5 & $4(7-11)$ & 41 & $20.5(0.7)$ & 20.5 & $1(20-21)$ \\
\hline \multirow{5}{*}{ Embryos/Blastocysts } & 297 & $10.2(3.8)$ & 9 & $5-20$ & 237 & $14.8(8.7)$ & 13 & 4-42 \\
\hline & \multicolumn{4}{|c|}{ Age $\leq 35$ y $(n=25)$} & \multicolumn{4}{|c|}{ Age $\leq 35$ y $(n=14)$} \\
\hline & 262 & $10.5(4.0)$ & 9 & $15(5-20)$ & 214 & $15.3(8.7)$ & 13 & $8-42$ \\
\hline & \multicolumn{4}{|c|}{ Age $>35$ y $(n=4)$} & \multicolumn{4}{|c|}{ Age $>35$ y $(n=2)$} \\
\hline & 35 & $8.7(1.7)$ & 8.5 & $4(7-11)$ & 23 & $11.5(10.6)$ & 11.5 & $4-19$ \\
\hline \multirow{5}{*}{ Fertilization rate } & 2772.4 & $59.3(17.7)$ & 100 & $25-100$ & 1429.3 & $89.3(22.2)$ & 100 & $19-100$ \\
\hline & \multicolumn{4}{|c|}{ Age $\leq 35$ y $(n=25)$} & \multicolumn{4}{|c|}{ Age $\leq 35$ y $(n=14)$} \\
\hline & 1450.5 & $58.0(18.4)$ & 53.8 & $75(25-100.0)$ & 1315.3 & $94.0(12.8)$ & 100 & $53.3-100.0$ \\
\hline & \multicolumn{4}{|c|}{ Age $>35$ y $(n=4)$} & \multicolumn{4}{|c|}{ Age $>35$ y $(n=2)$} \\
\hline & 269.9 & $67.5(9.8)$ & 67.9 & $\begin{array}{c}21.5(56.3- \\
77.8)\end{array}$ & 114 & $57.0(53.7)$ & 57.0 & $19-95$ \\
\hline Embryos/Blastocyst biopsied & 230 & $8.0(2.7)$ & 7 & $12(3-15)$ & 122 & $7.5(1.3)$ & 7.5 & $6-9$ \\
\hline Biopsy rate & 2401.1 & $80.9(20.9)$ & 85.7 & $\begin{array}{c}79(35.3- \\
114.3)\end{array}$ & 950.8 & $86.4(10.7)$ & 57.2 & $75-100.0$ \\
\hline No. of embryos/blastocysts with no results & 61 & $2.1(2.8)$ & 2 & $14(0-14)$ & 6 & $0.4(0.7)$ & 0 & $2(0-2)$ \\
\hline No. of cycles with no normal embryo/blastocyst & 9 & - & - & - & 0 & - & - & - \\
\hline No. of cycles with at least one normal & 20 & - & - & - & 16 & - & - & - \\
\hline Total No. of cycles & 29 & - & - & - & 16 & - & - & - \\
\hline Cancellation rate & There was & significant differ & cce in the & oportion of Day & ancellatior & rate compared t & Jay $5\left(x^{2}=\right.$ & P-value $=0.04)$ \\
\hline
\end{tabular}

Table 2: Oocyst retrieval, fertilization rate and biopsy rate of day 3 embryos and day 5 blastocysts by age $($ years $)(! t=2.15, \mathrm{df}=5.05, \mathrm{P}-\mathrm{value}=0.04)$. 
Citation: Ajayi AB, Ajayi VD, Atiba AA, Oyetunji IO, Ehichioya J, et al. (2018) Assessment of Chromosomal Aneuploidy in Day 3 Cleavage-Stage Embryos and Day 5/6 Blastocysts from Indigenous Black Africans. Human Genet Embryol 8: 147. doi:10.4172/2161-0436.1000147

Page 6 of 10

3.07, $\mathrm{df}=473.4$, P-value=0.001). Overall, only $312(55.5 \%)$ of the 562 MII oocytes retrieved in the Day 3 embryos group were fertilized $-275(88.1 \%$; mean $[ \pm \mathrm{sd}]=11.0[4.7])$ from those aged $\leq 35$ years and only $37(11.9 \%$, mean $[ \pm \mathrm{sd}]=9.2[1.7])$ from older women with a statistically significant difference $(\mathrm{t}=4.5, \mathrm{df}=130.0, \mathrm{P}$-value $=0.00001)$. Similarly only $269(55.3 \%$; mean $[ \pm \mathrm{sd}]=16.8[8.6])$ of the $422 \mathrm{MII}$ oocytes retrieved in the Day $5 / 6$ blastocysts group were fertilized, $228(84.8 \%$; mean $[ \pm \mathrm{sd}]=16.3[9.1]$ in the younger age group and $41(15.2 \%$, mean $[ \pm \mathrm{sd}]=20.5[0.7])$ from older age group, indicating a significant difference $(\mathrm{t}=-6.9, \mathrm{df}=240.7, \mathrm{P}$-value $=0.00001)$. Of the 312 MII oocytes fertilized in Day 3 embryo group, 297 (95.2\%, mean $[ \pm \mathrm{SD}]=10.2[3.8])$ embryos hatched $-262(88.2 \%$, mean $[ \pm \mathrm{sd}]=$ $10.5[4.0])$ from younger women and $35(11.8 \%$, mean $[ \pm \mathrm{sd}]=8.7$ [1.7] from older women with a significant variation $(t=4.75, \mathrm{df}=96.05$, $\mathrm{P}$-value $=0.00001)$. In comparison, of the $269 \mathrm{MII}$ oocytes fertilized in Day 5/6 blastocyst group, $237(88.1 \%$, mean $[ \pm \mathrm{SD}]=14.8$ [8.7]) blastocysts eventually emerged $-214(90.3 \%$, mean $[ \pm \mathrm{sd}]=15.3[8.7])$ from those age $\leq 35$ years and $23(9.7 \%$, mean $[ \pm$ SD] $=11.5$ [10.6] from those aged $>35$ years $(\mathrm{t}=1.66, \mathrm{df}=25.3$, P-value $=0.05)$.

Of the 297 embryos from Day 3 embryo group, 230 (77.4\%) were biopsied and screened, 61 (26.5\%) of which had no results and the remaining $169-151(89.3 \%)$ from women aged $\leq 35$ years and 18 $(10.7 \%)$ from those aged $>35$ years - were analysed as shown in Table 3 , which also shows that of the 122 Day $5 / 6$ blastocysts screened, 6 had no results and the remaining 116 Day 5/6 blastocysts, 104 (89.7\%) from those aged $\leq 35$ and $12(10.3 \%)$ from $>35$ years old women were finally analysed for pre-implantation chromosomal errors (Table 3). Women aged $\leq 35$ years had Day 3 embryo euploidy rate of $25.8 \%(39 / 151)$ while those aged $>35$ years had Day 3 euploidy rate of $11.1 \%(2 / 18)$. Women aged $\leq 35$ years were approximately thrice as likely to have euploid Day 3 embryos (Fisher's $\chi^{2}=1.18$, p-value $=0.29$, OR $=2.79,95 \%$ CI: $0.61,12.67)$ while the chances of aneuploidy in both age groups are relatively the same.(Fisher's $\chi^{2}=0.12, \mathrm{P}$-value $=0.72$, OR $=1.0,95 \%$ CI: $0.25,3.97)$, indicating a higher prevalence of euploidy in Day 3 embryo in women aged $\leq 35$ years compared to older women.

Table 4 illustrates the different types of aneuploidy observed in the samples of Day 3 embryos biopsied relative to the age of the women. The most prevalent aneuploidy in women aged $\leq 35$ years were complex $(35,31.2 \%), 1$ trisomy $(19,17.0 \%), 1$ monosomy $(16,14.3 \%)$ and 1 monosomy and 1 trisomy $(12(10.7 \%)$ while the most prevalent aneuploidy among those aged $>35$ years were complex $(9,56.3 \%)$ and 1 trisomy $(3,18.8 \%)$. The proportion of women aged $>35$ with complex aneuploidy $(9,56.3 \%)$ was significantly higher $\left(\chi^{2}=3.89, \mathrm{P}\right.$-value $\left.=0.04\right)$ than that of younger women $(35,31.2 \%)$. Further, compared to their younger counterparts, women aged $>35$ years were 1.13 times as likely to have 1 trisomy $\left(\chi^{2}=0.03, \mathrm{P}\right.$-value $=0.86, \mathrm{OR}=1.13,95 \% \mathrm{CI}$ :
$0.29,4.35) ; 1.43$ as likely to have 2 trisomy $\left(\chi^{2}=0.10, P\right.$-value $=0.75$, $\mathrm{OR}=1.43,95 \%$ CI: $0.16,13.06) ; 3.67$ times more likely to have 2 monosomy and 2 trisomy $\left(\chi^{2}=0.05, \mathrm{P}\right.$-value $=0.83, \mathrm{OR}=3.67,95 \% \mathrm{CI}$ : $0.31,42.93)$; approximately $7 \frac{1}{2}$ times as likely to have 3 monosomy and 1 trisomy $\left(\chi^{2}=0.29, P\right.$-value $=0.59, \mathrm{OR}=7.49,95 \%$ CI: $\left.0.44,124.62\right)$ and about thrice as likely to have complex aneuploidy (OR=2.82, 95\% CI: $0.97,8.21)$. Other types of aneuploidy were in low frequencies in both age groups. The table also shows that the ratio of different types of aneuploidy in Day 5/6 blastocysts of women aged over 35 years compared to younger women was 1:17 as only one (1) aneuploidy was observed in the blastocysts of women aged $>35$ years, compared to 17 in the blastocysts of those aged 35 years and below.

All-in-all, in Day 3 embryos, there were 23 (20.5\%) monosomies, $31(27.7 \%)$ trisomies, $23(20.5 \%)$ combinations of monosomies and trisomies and 35 (31.3\%) complex aneuploidy observed in women aged $\leq 35$ years compared to no $(0.0 \%)$ monosomy, 4 (25.0\%) trisomies, $3(18.8 \%)$ combinations of monosomy and trisomy and $9(56.2 \%)$ complex aneuploidy among older women. In addition, there were 8 (47.0\%) monosomy, 6 (35.3\%) trisomy, 2 (11.8\%) combinations of monosomy and trisomy and 1 (5.9\%) complex aneuploidy in blastocysts of women aged $\leq 35$ years compared to only $1(100.0 \%)$ monosomy in women aged $>35$ years (Table 5 and Figure 2).

The percentages of monosomies and trisomies seen in all Day 3 embryos are illustrated in Figure 3. The bulk (34.4\%) of the aneuploidy in Day 3 embryos comprised of complex aberration, followed by 1 trisomy (17.2\%), 1 monosomy (12.5\%) and 1 monosomy and 1 trisomy (9.4\%). Other aneuploidy in lower prevalence included 2 trisomy (4.7\%), 2 monosomies (3.9\%), 4 trisomies (3.1\%).

The prevalence of various monosomies and trisomies, and the combinations of these in Day 5/6 blastocysts are shown in Figure 4. The largest prevalence was in 1 monosomy (50.0\%) followed by 1 trisomy (28.0\%). Complex aneuploidy and 5 trisomies had a prevalence of $6.0 \%$ respectively while the combination of 1 monosomy and 1 trisomy as well as 2 monosomies and 1 trisomy each had a prevalence of $5.0 \%$.

Table 6 and Figures 5 and 6 indicate that, in the Day 3 embryos, a very low prevalence (0-3.99) of aneuploidy was observed in chromosomes 3, 7 and 8; low prevalence of 4-5.99 was observed in chromosomes 11, 12, 17 and Y; a moderate prevalence of 6-7.99 in chromosomes 4, 13 and $\mathrm{X}$ indicating that chromosome $\mathrm{X}$ was more affected in aneuploidy than chromosome Y. High aneuploidy prevalence of 8-9.99 was recorded in 5 chromosomes: 2, 5, 10, 18 and 22; very high aneuploidy prevalence of 10-14.99 observed in 7 chromosomes: 1, 6, 9, 14, 15, 16 and 19 and extremely high aneuploidy prevalence of 15-20.99 was observed in 2 chromosomes - 20 and 21 . This indicates that, among indigenous Black Africans, very low aneuploidy prevalence occurred in

\begin{tabular}{|c|c|c|c|c|c|c|c|}
\hline \multirow{2}{*}{ Variables } & \multirow{2}{*}{$\begin{array}{c}\text { Item } \\
\text { Age group (yrs.) }\end{array}$} & \multicolumn{3}{|c|}{ Day 3 Embryo } & \multicolumn{3}{|c|}{ Blastocyst } \\
\hline & & $\leq 35$ & $>35$ & All & $\leq 35$ & $>35$ & All \\
\hline \multirow{2}{*}{ Screened } & Frequency & 151 & 18 & 169 & 104 & 12 & 116 \\
\hline & $\%$ & 89.3 & 10.7 & 100.0 & 89.7 & 10.3 & 100.0 \\
\hline \multirow{2}{*}{ Euploid } & Frequency & 39 & 2 & 41 & 78 & 9 & 87 \\
\hline & $\%$ & 25.8 & 11.1 & 24.3 & 75.0 & 75.0 & 75.0 \\
\hline \multirow{2}{*}{ Aneuploid } & Frequency & 112 & 16 & 128 & 26 & 3 & 29 \\
\hline & $\%$ & 74.2 & 88.9 & 75.7 & 25.0 & 25.0 & 25.0 \\
\hline \multirow{4}{*}{ Statistics } & $x^{2}$ & \multicolumn{2}{|c|}{$1.18^{*}$} & - & \multicolumn{2}{|c|}{$0.12^{*}$} & - \\
\hline & $\mathrm{P}$-value & \multicolumn{2}{|c|}{0.29} & - & \multicolumn{2}{|c|}{0.72} & - \\
\hline & Odds ratio & \multicolumn{2}{|c|}{2.79} & - & \multicolumn{2}{|c|}{1.0} & - \\
\hline & $95 \% \mathrm{Cl}$ & \multicolumn{2}{|c|}{$0.61,12.67$} & - & \multicolumn{2}{|c|}{$0.25,3.97$} & - \\
\hline
\end{tabular}

Table 3: Prevalence of euploidy in day 3 embryos and in Day 5 blastocysts in different age groups. 
Citation: Ajayi AB, Ajayi VD, Atiba AA, Oyetunji IO, Ehichioya J, et al. (2018) Assessment of Chromosomal Aneuploidy in Day 3 Cleavage-Stage Embryos and Day 5/6 Blastocysts from Indigenous Black Africans. Human Genet Embryol 8: 147. doi:10.4172/2161-0436.1000147

Page 7 of 10

\begin{tabular}{|c|c|c|c|c|c|c|c|c|c|c|c|}
\hline \multirow{2}{*}{ Variables } & \multirow{3}{*}{ Item } & \multicolumn{4}{|c|}{ Age group (years) } & \multicolumn{4}{|c|}{ Statistics } & \multirow{2}{*}{\multicolumn{2}{|c|}{ Total $(n=128)$}} \\
\hline & & \multicolumn{2}{|c|}{$\leq 35$} & \multicolumn{2}{|c|}{$>35$} & \multirow{2}{*}{$\mathrm{x}^{2}$} & \multirow{2}{*}{ P-value* } & \multirow{2}{*}{ OR } & \multirow{2}{*}{$95 \% \mathrm{Cl}$} & & \\
\hline \multirow{21}{*}{ 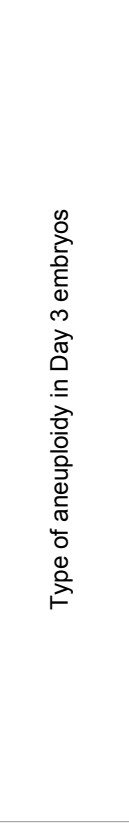 } & & Freq. & $\%$ & Freq. & $\%$ & & & & & Freq. & $\%$ \\
\hline & 1 Monosomy & 16 & 14.3 & 0 & 0.0 & 1.47 & 0.22 & - & - & 16 & 12.5 \\
\hline & 1 Trisomy & 19 & 17.0 & 3 & 18.8 & 0.03 & 0.86 & 1.13 & $0.29,4.35$ & 22 & 17.2 \\
\hline & 1 Monosomy \& 1 Trisomy & 12 & 10.7 & 0 & 0.0 & 0.84 & 0.34 & - & - & 12 & 9.4 \\
\hline & 1 Monosomy \& 2 Trisomy & 1 & 0.9 & 0 & 0.0 & 1.30 & 0.25 & - & - & 1 & 0.8 \\
\hline & 2 Monosomy & 5 & 4.5 & 0 & 0.0 & 0.03 & 0.86 & - & - & 5 & 3.9 \\
\hline & 2 Trisomy & 5 & 4.5 & 1 & 6.3 & 0.10 & 0.75 & 1.43 & $0.16,13.06$ & 6 & 4.7 \\
\hline & 2 Monosomy \& 2 Trisomy & 2 & 1.8 & 1 & 6.3 & 0.05 & 0.83 & 3.67 & $0.31,42.93$ & 3 & 2.3 \\
\hline & 3 Monosomy & 1 & 0.9 & 0 & 0.0 & 1.30 & 0.25 & - & - & 1 & 0.8 \\
\hline & 3 Trisomy & 2 & 1.8 & 0 & 0.0 & 0.29 & 0.59 & - & - & 2 & 1.6 \\
\hline & 3 Monosomy \& 1 Trisomy & 1 & 0.9 & 1 & 6.3 & 0.29 & 0.59 & 7.49 & $0.44,124.62$ & 2 & 1.6 \\
\hline & 3 Monosomy \& 3 Trisomy & 0 & 0.0 & 1 & 6.3 & 1.30 & 0.25 & - & - & 1 & 0.8 \\
\hline & 3 Trisomy \& 1 Monosomy & 3 & 2.7 & 0 & 0.0 & 0.05 & 0.82 & - & - & 3 & 2.3 \\
\hline & 4 Monosomy & 1 & 0.9 & 0 & 0.0 & 1.30 & 0.25 & - & - & 1 & 0.8 \\
\hline & 4 Trisomy & 4 & 3.6 & 0 & 0.0 & 0.00 & 1.00 & - & - & 4 & 3.1 \\
\hline & 4 Monosomy \& 1 Trisomy & 1 & 0.9 & 0 & 0.0 & 1.30 & 0.25 & - & - & 1 & 0.8 \\
\hline & 4 Monosomy \& 2 Trisomy & 2 & 1.8 & 0 & 0.0 & 0.29 & 0.59 & - & - & 2 & 1.6 \\
\hline & 5 Monosomy \& 2 Trisomy & 1 & 0.9 & 0 & 0.0 & 1.30 & 0.25 & - & - & 1 & 0.8 \\
\hline & 6 Trisomy & 1 & 0.9 & 0 & 0.0 & 1.30 & 0.35 & - & - & 1 & 0.8 \\
\hline & Complex & 35 & 31.2 & 9 & 56.3 & 3.88 & 0.04 & 2.83 & $0.97,8.21$ & 44 & 34.4 \\
\hline & Total & 112 & 87.5 & 16 & 12.5 & - & - & - & - & 128 & 100.0 \\
\hline \multirow{7}{*}{ 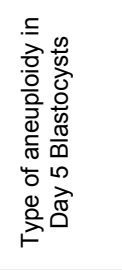 } & 1 Monosomy & 8 & 47.0 & 1 & 100.0 & 0.00 & 1.00 & - & - & 9 & 50.0 \\
\hline & 1 Trisomy & 5 & 29.4 & 0 & 0.0 & 0.26 & 0.52 & - & - & 5 & 27.8 \\
\hline & 1 Monosomy \& 1 Trisomy & 1 & 5.9 & 0 & 0.0 & 4.0 & 0.04 & - & - & 1 & 5.6 \\
\hline & 2 Monosomy \& 1 Trisomy & 1 & 5.9 & 0 & 0.0 & 4.0 & 0.04 & - & - & 1 & 5.6 \\
\hline & 5 Trisomy & 1 & 5.9 & 0 & 0.0 & 4.0 & 0.04 & - & - & 1 & 5.6 \\
\hline & Complex & 1 & 5.9 & 0 & 0.0 & 4.0 & 0.04 & - & - & 1 & 5.6 \\
\hline & Total & 17 & 94.4 & 1 & 5.6 & - & - & - & - & 18 & 100.0 \\
\hline
\end{tabular}

Fisher's exact. Only one (1) aneuploidy was observed in blastocysts of women aged $>35$ years compared to 17 among those aged $\leq 35$ years. Table 4: Types (not chromosome specific) of aneuploidies found in different age groups.

\begin{tabular}{|c|c|c|c|c|c|c|c|c|}
\hline \multirow{3}{*}{ Type of aneuploidy } & \multicolumn{4}{|c|}{ Day 3 embryo } & \multicolumn{4}{|c|}{ Blastocyst } \\
\hline & \multicolumn{2}{|c|}{ Age group $\leq 35$ years } & \multicolumn{2}{|c|}{ Age group $>35$ years } & \multicolumn{2}{|c|}{ Age group $\leq 35$ years } & \multicolumn{2}{|c|}{ Age group $>35$ years } \\
\hline & Freq. & $\%$ & Freq. & $\%$ & Freq. & $\%$ & Freq. & $\%$ \\
\hline Monosomy & 23 & 20.5 & 0 & 0.0 & 8 & 47.0 & 1 & 100.0 \\
\hline Trisomy & 31 & 27.7 & 4 & 25.0 & 6 & 35.3 & 0 & 0.0 \\
\hline Combination of monosomy and trisomy & 23 & 20.5 & 3 & 18.8 & 2 & 11.8 & 0 & 0.0 \\
\hline Complex & 35 & 31.2 & 9 & 56.2 & 1 & 5.9 & 0 & 0.0 \\
\hline All & 112 & 100.0 & 16 & 100.0 & 17 & 100.0 & 1 & 100.0 \\
\hline
\end{tabular}

Table 5: Aggregate number of aneuploidy in day 3 embryos and day 5 blastocysts among women of different age groups.

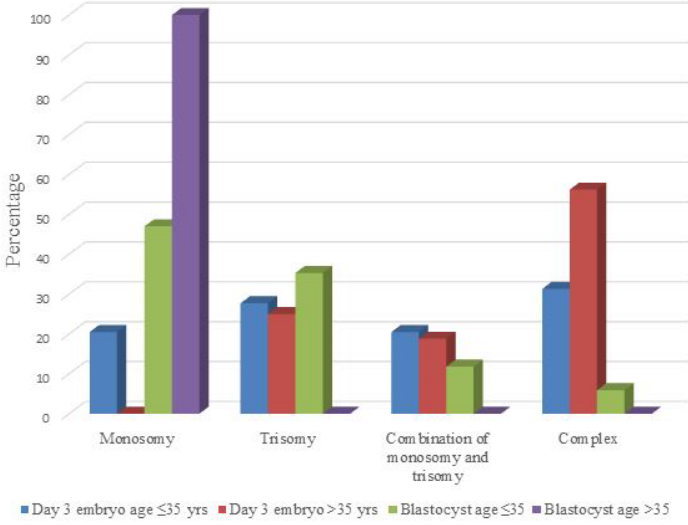

Figure 2: Percent distribution of various types of aneuploidy in age groups $\leq 35$ years and $>35$ years.

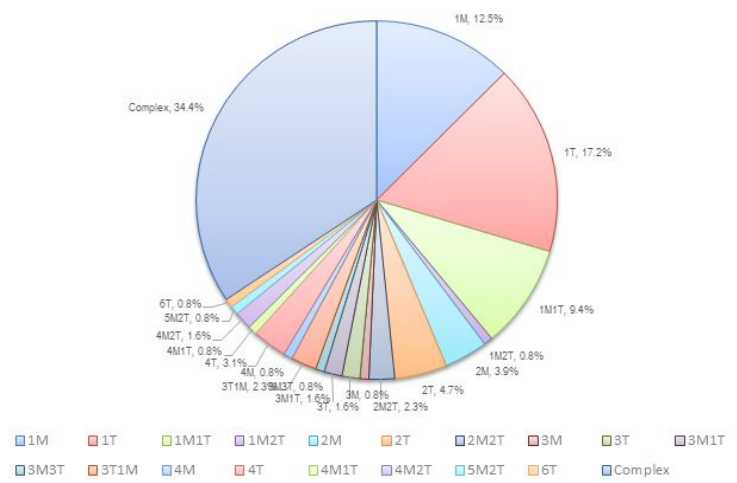

Figure 3: Percentage of monosomies and trisomies seen in biopsied day 3 embryos in Nigeria. 


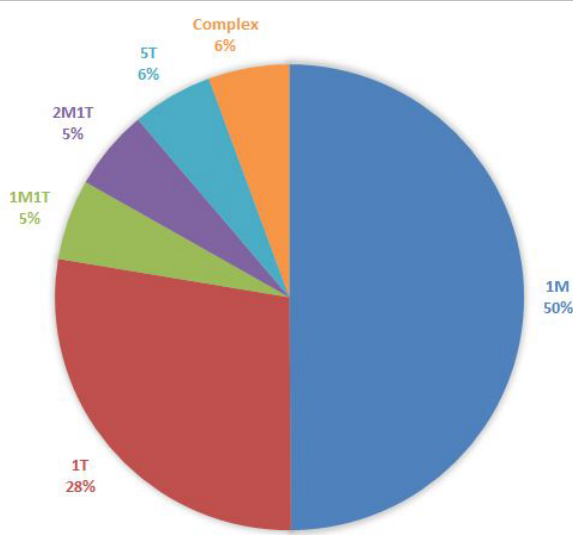

Figure 4: Percentage of monosomies and trisomies observed in biopsied day 5 blastocysts in Nigeria.

\begin{tabular}{|c|c|c|c|c|}
\hline \multicolumn{3}{|c|}{ Day 3 embryo } & \multicolumn{2}{|c|}{ Blastocyst } \\
\hline $\begin{array}{l}\text { Chromo- } \\
\text { some num- } \\
\text { ber }\end{array}$ & $\begin{array}{l}\text { No. of embryos } \\
\text { with aneuploidy }\end{array}$ & $\begin{array}{c}\text { Prevalence } \\
\%=\text { no. } \\
\text { Aneu/84 }\end{array}$ & $\begin{array}{c}\text { No. of } \\
\text { blastocysts } \\
\text { with aneuploidy }\end{array}$ & $\begin{array}{c}\text { Prevalence } \\
\%=\text { no. } \\
\text { Aneu/84 }\end{array}$ \\
\hline 1 & 11 & 13.09 & 2 & 11.76 \\
\hline 2 & 7 & 8.33 & 3 & 17.65 \\
\hline 3 & 3 & 3.57 & 1 & 5.88 \\
\hline 4 & 6 & 7.14 & 1 & 5.88 \\
\hline 5 & 7 & 8.33 & 0 & 0.00 \\
\hline 6 & 9 & 10.71 & 3 & 17.65 \\
\hline 7 & 3 & 3.57 & 0 & 0.00 \\
\hline 8 & 3 & 3.57 & 0 & 0.00 \\
\hline 9 & 12 & 14.28 & 0 & 0.00 \\
\hline 10 & 7 & 8.33 & 2 & 11.76 \\
\hline 11 & 4 & 4.76 & 2 & 11.76 \\
\hline 12 & 4 & 4.76 & 0 & 0.00 \\
\hline 13 & 6 & 7.14 & 0 & 0.00 \\
\hline 14 & 9 & 10.71 & 0 & 0.00 \\
\hline 15 & 9 & 10.71 & 2 & 11.76 \\
\hline 16 & 10 & 11.90 & 1 & 5.88 \\
\hline 17 & 4 & 4.76 & 0 & 0.00 \\
\hline 18 & 7 & 8.33 & 2 & 11.71 \\
\hline 19 & 11 & 13.09 & 1 & 5.88 \\
\hline 20 & 16 & 19.05 & 0 & 0.00 \\
\hline 21 & 17 & 20.23 & 1 & 5.88 \\
\hline 22 & 8 & 9.52 & 1 & 5.88 \\
\hline$x$ & 6 & 7.14 & 2 & 11.76 \\
\hline$Y$ & 5 & 5.95 & 0 & 0.00 \\
\hline
\end{tabular}

Table 6: Aneuploidy prevalence for different chromosomes in day 3 embryos and blastocysts (excluding number of complex abnormal).

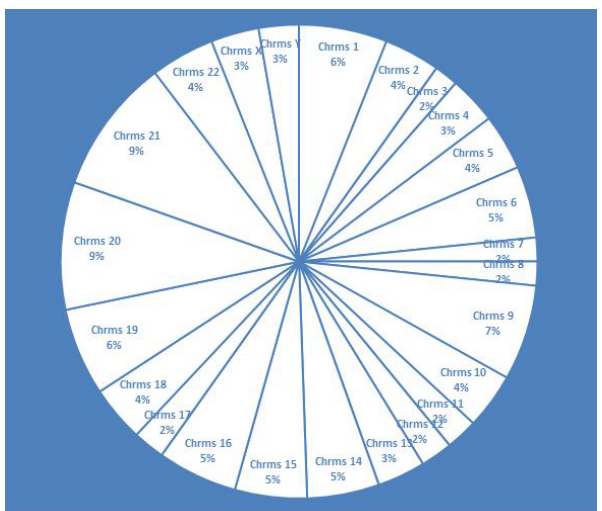

Figure 5: Aneuploidy prevalence for different chromosomes in day 3 embryos

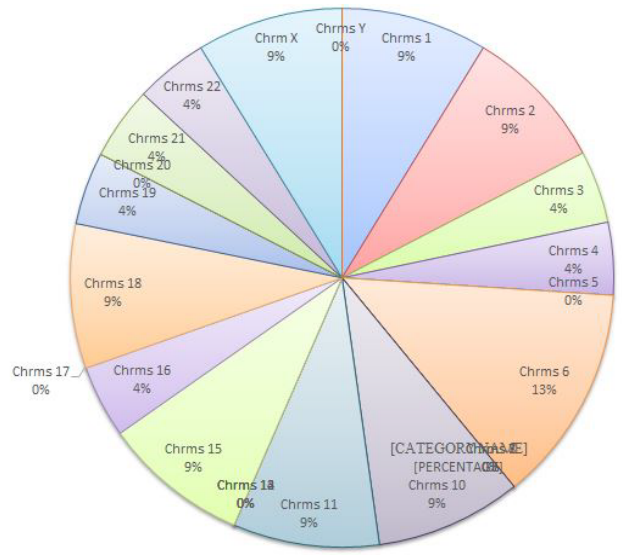

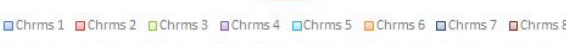
aChrms 9 aChrms $10 \square$ Chrms $11 \square$ Chrms $12 \square$ Chrms $13 \square$ Chrms $14 \square$ Chrms $15 \square$ Chrms 16

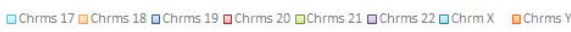

Figure 6: Aneuploidy prevalence for different chromosomes in day-5 blastocysts.

chromosomes 7 and 8 of both Day 3 embryos and Day 5/6 blastocysts, low prevalence of aneuploidy occurred in chromosome $\mathrm{Y}$ only in Day 3 embryos and not in Day 5/6 blastocysts, moderately high prevalence of aneuploidy occurred in chromosome $\mathrm{X}$ in Day 3 embryos while very high aneuploidy prevalence occurred in X chromosome of Day $5 / 6$ blastocysts. Chromosome 15 also suffered very high prevalence of aneuploidy in Day 3 embryos and Day 5/6 blastocysts. In the final analysis, 3 chromosomes in Day 3 embryos had very low aneuploidy prevalence compared to 9 in Day $5 / 6$ blastocysts. This number increased from 3 to 4 in Day 3 embryos with low prevalence of aneuploidy and decreased from 9 to 6 in Day 5/6 blastocysts.

In Day 5/6 blastocysts, very low prevalence (0-3.99) of aneuploidy was observed in chromosomes 5, 7, 8, 9, 12, 13, 14, 17 and 20; low prevalence (4-5.99) in chromosomes 3, 4, 16, 19, 21 and 22; there was no moderately high (6.7.99) or high (8-9.99) aneuploidy prevalence observed. However, very high (10-14.99) aneuploidy prevalence was seen in chromosomes $1,10,11,15,18$ and $\mathrm{X}$ while extremely high aneuploidy prevalence was observed in chromosomes 2 and 6 .

\section{Discussion}

This study, as far as we know, is the first study to analyze and characterize aneuploidy formation in Day 3 human embryos in comparison to Day 5 human blastocysts produced by IVF among indigenous Black African women. It is a well-known fact that the quality and appropriate selection of embryo are critical standards for transfer and eventual achievement of the goal of assisted reproductive technologies (ART). Also, the transfer of good quality embryos is associated with increased implantation, pregnancy and live birth rates and also decreased pregnancy loss and prenatal complications in comparison with transfer of embryos with impaired quality.

Previous studies have shown that the success of IVF is drastically reduced when an aneuploid embryo is transplanted, if such embryos are not screened for defect. Thus, it is suggested that transfer of aneuploid embryo could be minimized if there is a screening process to select euploid embryos for transfer. The overall Day 3 embryo euploidy rate of $24.3 \%$ observed in this study is similar to the $27.7 \%$ earlier reported in USA [25] and the overall Day 5 blastocyst euploidy rate of $75.0 \%$ in this study is higher than the $36.7 \%$ reported by Yu Su et al. [31] and the $60.9 \%$ reported by Haddard et al., [31] after pre-implantation genetic 
Citation: Ajayi AB, Ajayi VD, Atiba AA, Oyetunji IO, Ehichioya J, et al. (2018) Assessment of Chromosomal Aneuploidy in Day 3 Cleavage-Stage Embryos and Day 5/6 Blastocysts from Indigenous Black Africans. Human Genet Embryol 8: 147. doi:10.4172/2161-0436.1000147

Page 9 of 10

screening. This suggests that as in similar studies of pre-implantation of another racial origin, the culture of embryos to blastocysts in black African pre-implantation embryos eliminates aneuploidy in cleavage stage embryos to a certain extent through some sort of self-correction mechanism. However, it is important to note that blastocyst culture alone is not a total eradication of aneuploidy as some studies have shown that the attrition of embryos from day 3 to day 5 is largely due to aneuploidy [50].

Considering age and aneuploidy rate, many studies have observed significant decreasing euploidy rate with advancing age. [51] observed a proportion of euploid embryos in women $\leq 35$ years as $35 \%$ in day 3 embryos and rapidly declined to $0 \%$ by age 44 . Harton et al., [52] also showed a similar trend of euploidy rate with increasing age. Similarly, we also observed a decrease in day 3 euploidy rate with advancing age, women aged $\leq 35$ had Day 3 euploidy rate of $25.8 \%$ while those $>35$ had euploidy rate of $11.1 \%$. Interestingly also, it was discovered that although the aneuploidy rate of women $>35$ was significantly higher compared to aneuploidy of younger women in the cleavage group, the situation was different in the blastocyst group as women in the two age groups has similar euploidy rates. These evidences can be useful in the assisted reproductive treatment of older women using own eggs to consider the combination of blastocyst culture and PGS to select euploid embryos for transfer and improve the efficiency of having not just an offspring but healthy offspring at an advanced age.

Some have suggested that aneuploidies in chromosomes 1 to 12 is more common in cleavage stage embryos as these do not persist to the blastocyst stage, [53] however, aneuploidies in chromosomes 13, 18, 21 are able to persist throughout development and are also compatible with life. Another study suggests at the cleavage stage, aneuploidies affect chromosomes 15, 16, 21 and 22 most frequently and chromosomes $X$ and $\mathrm{Y}$ least frequently [54] similar to our study with high prevalence of $10.71 \%, 11.90 \%, 20.23 \%, 9.52 \%$ for chromosomes 15, 16, 21, 22 and a lower prevalence of $7.14 \%$ and $5.95 \%$ for $\mathrm{X}$ and $\mathrm{Y}$ respectively.

Furthermore, we observed a significant decrease in prevalence of chromosome $13(0.00 \%)$ and chromosome 21 (5.88) aneuploidies at the blastocyst stage compared to $7.14 \%$ and $20.23 \%$ observed respectively at the cleavage stage, supporting suggestions that embryos to blastocyst stage may genetically select those that are competent among them.

\section{Conclusion}

As evidenced by our study, blastocyst stage biopsy appears to be the most efficient stage of biopsy in PGS, by retrieving 3-10 trophectoderm cells; more DNA material is available thus improving the accuracy rate as seen with significantly lower rate of embryos with no results in the blastocyst group compared to the cleavage stage group. Another efficiency of the blastocyst stage biopsy can be evidenced as seen in this study with significantly higher euploidy rates in the blastocyst group compared to the cleavage stage group attesting to the fact that blastocyst culture is a form of abnormality screening for pre-implantation embryos. This study was also able to show that in indigenous Black Africans, blastocyst culture and PGS can be more effective in the ART treatment of women of advanced age to achieve pregnancy and live birth of a healthy child.

\section{Study Limitations}

Although the research has reached its aims, there was some unavoidable limitation. First, because PGS is a relatively new technology amongst indigenous Black Africans, this research was conducted only on a small sample size of population of those attending our IVF unit mainly for the purpose of sex selection by PGS. Therefore, to generalize the results for larger groups, the study should have involved more participants at different ages.

\section{Acknowledgement}

This research received no funding from any organization.

\section{Conflicts of Interest}

None.

\section{References}

1. Liu J, Wang W, Sun X, Liu L, Jin H, et al. (2012) DNA microarray reveals that high proportions of human blastocysts from women of advanced maternal age are aneuploidy and mosaic. Biol Reprod 87: 1-9.

2. Al-Asmar N, Peinado V, Vera M, Remohi J, Pellicer A, et al. (2012) Chromosomal abnormalities in embryos from couples with a previous aneuploid miscarriage. Fertil Steril 98: 145-150.

3. Franasiak JM, Forman EJ, Hong KH, Werner MD, Upham KM, et al. (2014) The nature of aneuploidy with increasing age of the female partner: a review of 15,169 consecutive trophectoderm biopsies evaluated with comprehensive chromosomal screening. Fertil Steril 101: 656-663.

4. Platteau P, Staessen C, Michiels A, Van Steirteghem A, Liebaers I, et al. (2005) Preimplantation genetic diagnosis for aneuploidy screening in women older than 37 years. Fertil Steril 84: 319-324.

5. Hassold T, Hunt $P$ (2001) To err (meiotically) is human: The genesis of human aneuploidy. Nat Rev Genet 2: 280-291.

6. Munné S, Fischer J, Warner A, Chen S, Zouves C, et al. (2006) Referring Centers PGD Group. Preimplantation genetic diagnosis significantly reduces pregnancy loss in infertile couples: A multicenter study. Fertil Steril 85: 326 332.

7. Munne S, Sandalinas M, Magli C, Gianaroli L, Cohen J, et al. (2004) Increased rate of aneuploid embryos in young women with previous aneuploid conceptions. Prenat Diagn 24: 638-643.

8. Baart EB, Martini E, Van den Berg I, Macklon NS, Galjaard RJH, et al. (2006) Pre-implantation genetic screening reveals a high incidence of aneuploidy and mosaicism in embryos from young women undergoing IVF. Hum Reprod 21: 223-233.

9. Vanneste E, Voet T, Le Caignec C, Ampe M, Konings P, et al. (2009) Chromosome instability is common in human cleavage-stage embryos. Nat Med 15: 577-583.

10. Fragouli E, Lenzi M, Ross R, Katz-Jaffe M, Schoolcraft WB, et al. (2008) Comprehensive molecular cytogenetic analysis of the human blastocyst stage. Hum Reprod 23: 2596-2608.

11. Wells D, Delhanty JD (2000) Comprehensive chromosomal analysis of human pre-implantation embryos using whole genome amplification and single cell comparative genomic hybridization. Mol Hum Reprod 6: 1055-1062.

12. Voullaire L, Slater H, Williamson R, Wilton $L$ (2000) Chromosome analysis of blastomeres from human embryos by using comparative genomic hybridization. Hum Genet 106: 210-217.

13. Munné S, Magli C, Bahçe M, Fung J, Legator M, et al. (1998) Preimplantation diagnosis of the aneuploidies most commonly found in spontaneous abortions and live births: XY, 13, 14, 15, 16, 18, 21, 22. Prenat Diagn 18: 1459-1466.

14. Warburton D, Kline J, Stein Z (1986) Cytogenetic abnormalities in spontaneous abortions of recognized conceptions. In: I.H Porter, A. Willey (eds). Perinatal genetics: diagnosis and treatment. New York: Academic Press p: 133

15. Bianco K, Caughey AB, Shaffer BL, Davis R, Norton ME (2006) History of miscarriage and increased incidence of fetal aneuploidy in subsequent pregnancy. Obstet Gynecol 107: 1098-1102.

16. Rubio C, Pehlivan T, Rodrigo L, Simón C, Remohí J, Pellicer, et al. (2005) Embryo aneuploidy screening for unexplained recurrent miscarriage: a mini review. Am J Reprod Immunol 53: 159-165.

17. Sullivan AE, Silver RM, LaCoursiere DY, Porter TF, Branch DW (2004) Recurrent fetal aneuploidy and recurrent miscarriage. Obstet Gynecol 104: 784-788.

18. Goldman B (2007) Reproductive medicine: The first cut. Nature 445: 479-480.

19. Hardy K, Martin KL, Leese HJ, Winston RM, Handyside AH (1990) Human pre-implantation development in vitro is not adversely affected by biopsy at the 8-cell stage. Hum Reprod 5: 708-714. 
Citation: Ajayi AB, Ajayi VD, Atiba AA, Oyetunji IO, Ehichioya J, et al. (2018) Assessment of Chromosomal Aneuploidy in Day 3 Cleavage-Stage Embryos and Day 5/6 Blastocysts from Indigenous Black Africans. Human Genet Embryol 8: 147. doi:10.4172/2161-0436.1000147

Page 10 of 10

20. Sermon K, Van Steirteghem A, Liebaers I (2004) Preimplantation genetic diagnosis. Lancet 363: 1633-1641.

21. Brodie D, Beyer CE, Osborne E, Kralevski V, Rasi S, et al. (2012) Preimplantation genetic diagnosis for chromosome rearrangements - One blastomere biopsy versus two blastomere biopsy. J Assist Reprod Gene 29: 821-827.

22. De Vos A, Staessen C, De Rycke M, Verpoest W, Haentjens P, et al. (2009) Impact of cleavage-stage embryo biopsy in view of PGD on human blastocyst implantation: A prospective cohort of single embryo transfers. Hum Reprod 24 2988-2996.

23. Goossens V, Traeger-Synodinos J, Coonen E, De Rycke M, Moutou C, et al. (2014) ESHRE PGD Consortium data collection XII: cycles from January to December 2009 with pregnancy follow-up to October 2010. Hum Reprod 29 880-903.

24. Verpoest W, Fauser BC, Papanikolaou E, Staessen C, Van Landuyt L, et al. (2008) Chromosomal aneuploidy in embryos conceived with unstimulated cycle IVF. Hum Reprod 23: 2369-2371.

25. Rabinowitz M, Ryan A, Gemelos G, Hill M, Baner J, et al. (2012) Origins and rates of aneuploidy in human blastomeres. Fertil Steril 97: 395-401.

26. Pagidas K, Ying $Y$, Keefe $D$ (2008) Predictive value of pre-implantation genetic diagnosis for aneuploidy screening in repeated IVF-ET cycles among women with recurrent implantation failure. J Assist Reprod Genet 25: 103-106.

27. Su Y, Li J, Wang C, Haddad G, Wang W (2016) Aneuploidy analysis in day 7 human blastocysts produced by in vitro fertilization. Reprod Biol Endocrinol 14: $14: 20$

28. Griffin DK (1996) The incidence, origin, and etiology of aneuploidy. Int Rev Cytol 167: 263-296.

29. Munné S, Chen S, Colls P, Garrisi J, Zheng X, et al. (2007) Maternal age, morphology, development and chromosome abnormalities in over 6000 cleavage-stage embryos. Reprod Biomed Online 14: 628-634.

30. Kuwayama M, Vajta G, Kato O, Leibo SP (2005) Highly efficient vitrification method for cryopreservation of human oocytes. BioMedicine Online 11: 300-308.

31. Haddad G, Deng M, Wang CT, Witz C, Williams D, et al. (2015) Assessment of aneuploidy formation in human blastocysts resulting from donated eggs and the necessity of the embryos for aneuploidy screening. J Assist Reprod Gene 32: 999-1006.

32. McArthur SJ, Leigh D, Marshall JT, De Boer KA, Jansen RP (2005) Pregnancies and live births after trophectoderm biopsy and preimplantation genetic testing of human blastocysts. Fertil Steril 84: 1628-1636.

33. Munné S, Bahçe M, Sandalinas M, Escudero T, Márquez C, et al. (2004) Differences in chromosome susceptibility to aneuploidy and survival to first trimester. Reprod Biomed Online 8: 81-90.

34. Silber S, Escudero T, Lenahan K, Abdelhadi I, Kilani Z, et al. (2003) Chromosomal abnormalities in embryos derived from testicular sperm extraction. Fertil Steril 79: $30-38$.

35. Platteau $P$, Staessen $C$, Michiels A, Tournaye $H$, Van Steirteghem A, et al. (2004) Comparison of the aneuploidy frequency in embryos derived from testicular sperm extraction in obstructive and non-obstructive azoospermic men. Hum Reprod 19: 1570-1574.

36. Donoso P, Platteau EG, Papanikolaou C, Staessen A, Van Steirteghem P, et al. (2006) Does PGD for aneuploidy screening change the selection of embryos derived from testicular sperm extraction in obstructive and non-obstructive azoospermic men? Hum Reprod 21: 2390-2395.

37. Munné S, Ary J, Zouves C, Escudero T, Barnes F, et al. (2006) Wide range of chromosome abnormalities in the embryos of young egg donors. Reprod Biomed Online 12: 340-346.
38. Lucifero D, Chaillet JR, Trasler JM (2004) Potential significance of genomic imprinting defects for reproduction and assisted reproductive technology. Hum Reprod Update 10: 3-18.

39. Li M, DeUgarte CM, Surrey M, Danzer H, De Cherney A, et al. (2005) Fluorescence in situ hybridization reanalysis of day- 6 human blastocysts diagnosed with aneuploidy on day 3. Fertil Steril 84: 1395-1400.

40. Barbash-Hazan S, Frumkin T, Malcov M, Yaron Y, Cohen T, et al. (2009) Preimplantation aneuploid embryos undergo self-correction in correlation with their developmental potential. Fertil Steril 92: 890-896.

41. Northrop LE, Treff NR, Levy B, Scott RT Jr (2010) SNP microarray-based 24 chromosome aneuploidy screening demonstrates that cleavage-stage FISH poorly predicts aneuploidy in embryos that develop to morphologically normal blastocysts. Mol Hum Reprod 16: 590-600.

42. Munné S, Velilla E, Colls P, Garcia Bermudez M, Vemuri MC, et al. (2005) Selfcorrection of chromosomally abnormal embryos in culture and implications for stem cell production. Fertil Steril 84: 1328-1334.

43. Harton GL, Magli MC, Lundin K, Montag M, Lemmen J, at el. (2011) ESHRE PGD consortium/embryology special interest group-best practice guidelines for polar body and embryo biopsy for preimplantation genetic diagnosis/screening (PGD/PGS). Hum Reprod 26: 41-46.

44. Donoso P, Devroey P (2007) PGD for aneuploidy screening: An expensive hoax? Best Pract Res Clin Obstet Gynaecol 21: 157-168.

45. Fiorentino F, Biricik A, Bono S, Spizzichino L, Cotroneo E, et al. (2014) Development and validation of a next generation sequencing (NGS)-based protocol for 24-chromosome aneuploidy screening of embryos. Fertil Steril 101: $1375-1382$.

46. Rodrigo L, Mateu E, Mercader A, Cobo AC, Peinado V, et al. (2014) New tools for embryo selection: comprehensive chromosome screening by array comparative genomic hybridization. Biomed Res Int 2014: 517125.

47. Treff NR, Fedick A, Tao X, Devkota B, Taylor D, et al. (2013) Evaluation of targeted next-generation sequencing-based preimplantation genetic diagnosis of monogenic disease. Fertil Steril 99: 1377-1138.

48. Harper JC, Coonen E, De Rycke M, Harton G, Moutou C, et al. (2010) ESHRE PGD Consortium data collection X: cycles from January to December 2007 with pregnancy follow-up to October 2008. Hum Reprod 25: 2685-2707.

49. Yang Z, Lin J, Zhang J, Fong WI, Li P, et al. (2015) Randomized comparison of next-generation sequencing and array comparative genomic hybridization for pre-implantation genetic screening: a pilot study. BMC Med Genomics 8: 30 .

50. Schoolcraft WB, Fragouli E, Stevens J, Munne S, Katz-Jaffe MG, et al. (2009) Clinical application of comprehensive chromosomal screening at the blastocyst stage. Fertil Steril 94: 1700-1706.

51. Demko ZP, Simon AL, McCoy RC, Petrov DA, Rabinowitz M (2016) Effects of maternal age on euploidy rates in a large cohort of embryos analyzed with 24-chromosome single-nucleotide polymorphism-based preimplantation genetic screening. Fertil Steril 105: 1307-1313.

52. Harton GL, Munné S, Surrey M, Grifo J, Kaplan B, et al. (2013) Diminished effect of maternal age on implantation after preimplantation genetic screening with array comparative genomic hybridization. Fertil Steril 100: 1695-1703.

53. Brezina P, Barker A, Benner A, Ross R, Nguyen KH, et al. (2011) Genetic normalization of differentiating aneuploid human embryos. Nature Precedings: Pre-publication research and preliminary findings.

54. Munne S (2006) Chromosome abnormalities and their relationship to morphology and development of human embryos. Reprod Biomed Online 12: 234-253. 